\title{
Влияние природы подложки на состав пленок CdPbS и механические напряжения на интерфейсе „пленка-подложка“
}

\author{
(C) Л.Н. Маскаева ${ }^{1}$, А.В. Поздин ${ }^{1}$, В.Ф. Марков ${ }^{1,2}$, В.И. Воронин ${ }^{3}$ \\ ${ }^{1}$ Уральский фредеральный университет им. первого Президента России Б.Н. Ельцина, \\ 620002 Екатеринбург, Россия \\ 2 Уральский институт государственной противопожарной службы МЧС России, \\ 620062 Екатеринбург, Россия \\ ${ }^{3}$ Институт фоизики металлов им. М.Н. Михеева Уральского отделения Российской академии наук, \\ 620108 Екатеринбург, Россия \\ E-mail: mln@ural.ru
}

Поступила в Редакцию 17 августа 2020 г.

В окончательной редакции 24 августа 2020 г.

Принята к публикации 24 августа 2020 г.

Исследована роль подложки различной природы на фазовый состав, морфологию и механические напряжения на интерфейсе „пленка-подложка“ при химическом осаждении слоев $\mathrm{CdPbS}$ на кремнии (111), ситалле, плавленом кварце, ITO-покрытии, предметном и пористом стеклах. Высказано предположение, что выявленные особенности связаны с различными условиями зарождения и роста пленок. Установлено, что на плавленом кварце формируется однофазная пленка твердого раствора $\mathrm{Cd}_{x} \mathrm{~Pb}_{1-x} \mathrm{~S}$ в отличие от остальных субстратов, на которых осаждаются слои, содержащие дополнительно от 2 до 8 мол\% рентгеноаморфной фазы CdS. Показано, что увеличение величины механических напряжений сжатия на интерфейсе ,пленкаподложка“ с -9.32 до -121.79 кН/ м $^{2}$ в ряду пористое стекло-предметное стекло-ситалл-кремний (111)плавленый кварц асимбатно значениям температурных коэффициентов расширения этих подложечных материалов.

Ключевые слова: химическое осаждение, тонкие пленки, твердые растворы $\mathrm{Cd}_{x} \mathrm{~Pb}_{1-x} \mathrm{~S}$, механические напряжения сжатия.

DOI: 10.21883/FTP.2020.12.50230.9506

\section{1. Введение}

Уникальное сочетание электрофизических характеристик, варьирование которых позволяет рассматривать твердые растворы $\mathrm{Cd}_{x} \mathrm{~Pb}_{1-x} \mathrm{~S}$ как наиболее предпочтительный материал, обладающий большими потенциальными возможностями для создания ИК детекторов $[1,2]$, приборов экологического контроля [3,4], а также высокоэффективных солнечных элементов [5-7].

С развитием тонкопленочных технологий и уменышением размеров устройств актуальной помимо функциональных характеристик твердых растворов $\mathrm{Cd}_{x} \mathrm{~Pb}_{1-x} \mathrm{~S}$ (фотопроводимость, сенсорные свойства), становится проблема их механических характеристик, обеспечивающих стабильность нанесенных слоев на различные подложки, в качестве которых при химическом осаждении используется довольно широкий круг диэлектрических и проводящих материалов.

В литературе с учетом множества публикаций по влиянию условий химического осаждения пленок $\mathrm{Cd}_{x} \mathrm{~Pb}_{1-x} \mathrm{~S}$ на морфологию, состав, кристаллическую структуру и полупроводниковые свойства [8-17] практически не обсуждается вопрос о сравнительных исследованиях по влиянию на конечный результат синтеза материала подложки. В качестве подложечного материала для пленок $\mathrm{Cd}_{x} \mathrm{~Pb}_{1-x} \mathrm{~S}$ чаще всего используют предметное стекло $[10,12,14,17-19]$, а также ситалл $[3,4,13,16]$.
Известно также применение кремния, кварца и пористого стекла [20,21].

Неравновесность процесса химического осаждения слоев $\mathrm{Cd}_{x} \mathrm{~Pb}_{1-x} \mathrm{~S}[20]$, возникающие структурные изменения при замещении свинца кадмием в кристаллической решетке $\mathrm{PbS}$ [22], различная химическая природа материалов и несоответствие сопрягаемых решеток подложки и пленки, а также различия в их коэффициентах термического расширения [23] могут обусловливать микродеформации и высокие механические напряжения как в объеме тонкопленочных структур, так и на межфазной границе ,пленка-подложка“. Сведения о величине механических напряжений на границе „химически осажденная пленка-подложка“ крайне ограничены, хотя очень полезны для подбора материала подложек при создании функциональных устройств.

Одной из основных характеристик системы „пленкаподложка“ является их способность испытывать значительную деформацию при растягивающих и сжимающих воздействиях, что неизбежно приводит к растрескиванию или отслоению пленки от подложки. В технологии гетероэпитаксии пленки $\mathrm{PbS}$ на кремнии для устранения напряжений несоответствия и улучшения кристаллического совершенства растущего слоя электрохимическим травлением на поверхности кремниевой подложки создается тонкий сильно дефектный слой с пористой структурой, выполняющий функцию буфера [24]. Термическим испарением в [25] и химическим осаждением из газовой 
фазы в [26] показана возможность выращивания на кремнии с пористым буферным слоем ненапряженных эпитаксиальных пленок селенида цинка. Такой прием обеспечивает возможность „подстраивания“ подложки под кристаллическую решетку растущего кристалла и уменьшает механические напряжения несоответствия. Для прогнозирования поведения функциональных материалов и изготовления на их основе оптоэлектронных устройств необходимо знание величины возникающих напряжений на межфазных границах пленки с подложкой. В этом плане интерес представляет статья [27], в которой впервые представлены количественные характеристики механических напряжений на границе „пленка-ситалловая подложка“ для слоя $\mathrm{ZnSe}$, полученного химическим осаждением. Проведенные электронномикроскопические исследования пленки показали, что минимизация возникающих напряжений в процессе ее роста привела к растрескиванию слоя и релаксации напряжений в соседних областях. Что касается пленок твердых растворов $\mathrm{Cd}_{x} \mathrm{~Pb}_{1-x} \mathrm{~S}$, осаждаемых из водных растворов, то в литературе отсутствуют исчерпывающие экспериментальные данные, позволяющие сформулировать основные закономерности влияния материала подложки на их состав и микроструктуру, а также оценить деформационные искажения на межфазной границе „пленка-подложка“.

В связи с этим цель настоящей работы заключалась в оценке влияния природы подложки на фазовый и элементный состав, морфологические и структурные особенности химически осажденных пленок $\mathrm{Cd}_{x} \mathrm{~Pb}_{1-x} \mathrm{~S}$, a также на величину микродеформаций в их объеме и механических напряжений, возникающих на интерфейсе „пленка-подложка“.

\section{2. Методика эксперимента}

Пленки твердых растворов $\mathrm{Cd}_{x} \mathrm{~Pb}_{1-x} \mathrm{~S}$ толщиной 185-190 нм получали химическим осаждением из реакционной смеси, содержащей фиксированные концентрации ацетата свинца $\mathrm{Pb}\left(\mathrm{CH}_{3} \mathrm{COO}\right)_{2}$, хлорида кадмия $\mathrm{CdCl}_{2}$, цитрата натрия $\mathrm{Na}_{3} \mathrm{C}_{6} \mathrm{H}_{5} \mathrm{O}_{7}$, водного раствора аммиака $\mathrm{NH}_{4} \mathrm{OH}$ и тиомочевины $\mathrm{N}_{2} \mathrm{H}_{4} \mathrm{CS}$, выступающей в роли халькогенизатора (поставщика ионов серы).

В качестве подложек при осаждении пленок использовали как проводящие материалы, так и диэлектрические. Среди первых использовался ориентированный монокристаллический кремний (111) с постоянной кристаллической решетки $a=0.54307$ нм и электропроводностью $1 \mathrm{OM}^{-1}$, а также нанесенный на стекло слой ITO толщиной 100 нм, имеющий состав $\left(\mathrm{In}_{2} \mathrm{O}_{3}\right)_{0.9}\left(\mathrm{SnO}_{2}\right)_{0.1}$, кубическую структуру ОЦК с постоянной $a \sim 1.01-1.03 \mathrm{HM}$ и электропроводностью $0.1 \mathrm{OM}^{-1}$. Из диэлектрических материалов в качестве подложек использовали ситалл марки СТ-50-1 беспористый стеклокерамический материал, состоящий из кристаллических фаз рутила $\alpha-\mathrm{TiO}_{2}$ и кордиерита
$2 \mathrm{MgO} \cdot 2 \mathrm{Al}_{2} \mathrm{O}_{3} \cdot 5 \mathrm{SiO}_{2}$, скрепленных стекловидными прослойками, а также плавленый кварц (кварцевое стекло) - изотропное однокомпонентное соединение, состоящее из $\mathrm{SiO}_{2}$; предметное стекло (72.2\% $\mathrm{SiO}_{2}$, $14.3 \% \mathrm{Na}_{2} \mathrm{O} ; 1.2 \% \mathrm{~K}_{2} \mathrm{O}, 6.4 \%, 4.3 \% \mathrm{MgO}, 1.2 \% \mathrm{Al}_{2} \mathrm{O}_{3}$, $\left.0.03 \% \mathrm{FeO}, 0.3 \% \quad \mathrm{SO}_{3}\right)$, являющееся аморфным материалом, и пористое стекло марки ДВ-1 (7\% $\mathrm{Na}_{2} \mathrm{O}$, $\left.23 \% \mathrm{~B}_{2} \mathrm{O}_{3}, 70 \% \mathrm{SiO}_{2}\right)$ с диаметром пор 4.5-5.0 нм, полученных в результате выщелачивания стекла в растворе $\mathrm{HCl}$.

Синтез пленок осуществляли на предварительно подготовленные подложки в жидкостном термостате „ТС-ТБ-10“ в течение 30 мин при $353 \mathrm{~K}$ с точностью поддержания температуры $\pm 0.1 \mathrm{~K}$.

Оценку толщины полученных пленок проводили с помощью интерференционного микроскопа (микроинтерферометра Линника) МИИ-4М с погрешностью измерения, равной $20 \%$.

Микроструктуру и элементный состав пленок изучали с помощью растровых электронных микроскопов MIRA 3 LMU при ускоряющем напряжении электронного пучка 10 кВ и JEOL JSM-5900 LV с энерго-дисперсионным рентгеновским анализатором EDS Inca Energy 250.

Размер частиц определяли с помощью программного обеспечения Measurer с дальнейшей обработкой данных в пакете прикладных программ Microsoft Office Excel 2013 и Origin 9.0.

Рентгеновские спектры осажденных пленок снимали в интервале углов $2 \Theta=20-100^{\circ}$ с шагом $0.01^{\circ}$ и скоростью съемки 0.5 об/мин на дифрактометре Rigaku Mini Flex 600 (Rigaku, Япония). Уточнение структурных параметров пленок проводили с помощью полнопрофильного анализа Ритвелда [28,29] с использованием программы Fullprof [30]. Для разделения вкладов размера зерен и деформации в ширину дифракционных отражений использовали уравнение Уильямсона-Холла (conventional Williamson-Hall plot) [31],

$$
\beta \cdot \cos \Theta=0.9 \lambda / D+4 \varepsilon \cdot \sin \Theta,
$$

где $D-$ средний размер областей когерентного рассеяния, принимаемого за средний размер частиц, $\beta-$ полуширина рефлекса в радианах, $\lambda$ - длина волны используемого рентгеновского излучения, $\varepsilon=\Delta d / d-$ деформация, где $d$ - межплоскостное расстояние.

Приближенную оценку механических напряжений $\sigma_{\Delta \alpha}$ в двухслойной структуре „Пленка твердого раствора $\mathrm{Cd}_{x} \mathrm{~Pb}_{1-x} \mathrm{~S}$-подложка“ проводили по предложенной в работе [32] формуле

$$
\sigma_{\Delta \alpha}=\frac{6 \cdot E_{\mathrm{Cd}_{x} \mathrm{~Pb}_{1-x} S} \cdot\left(\alpha_{\mathrm{sub}}-\alpha_{\mathrm{Cd}_{x} \mathrm{~Pb}_{1-x} \mathrm{~S}}\right) \cdot h_{\mathrm{Cd}_{x} \mathrm{~Pb}_{1-x} \mathrm{~S}} \cdot \Delta T}{\left(1-v_{\mathrm{Cd}_{x} \mathrm{~Pb}_{1-x} \mathrm{~S}}\right) \cdot\left(3 h_{\mathrm{sub}}-4 h_{\mathrm{Cd}_{x} \mathrm{~Pb}_{1-x} \mathrm{~S}}\right)},
$$

где $E_{\mathrm{Cd}_{x} \mathrm{~Pb}_{1-x} \mathrm{~S}}-$ модуль Юнга для твердого раствора $\mathrm{Cd}_{x} \mathrm{~Pb}_{1-x} \mathrm{~S} ; \alpha_{\text {sub }}, \alpha_{\mathrm{Cd}_{x} \mathrm{~Pb}_{1-x} \mathrm{~S}}$ - температурные коэффициенты расширения подложки и пленки; $\Delta T-$ разность температур; $v_{\mathrm{Cd}_{x} \mathrm{~Pb}_{1-x} \mathrm{~S}}$ - коэффициент Пуассона пленки; 
$h_{\mathrm{sub}}, h_{\mathrm{Cd}_{x} \mathrm{~Pb}_{1-x} \mathrm{~S}}$ - толщины подложки и пленки, соответственно, при условии $h_{\text {sub }} \gg h_{\mathrm{Cd}_{x} \mathrm{~Pb}_{1-x} \mathrm{~S}}$.

Тип проводимости пленок определяли по знаку термоэдс при создании градиента температуры в области зондовых контактов.

\section{3. Результаты и их обсуждение}

\section{1. Морфология и элементный состав}

Образование твердого раствора $\mathrm{Cd}_{x} \mathrm{~Pb}_{1-x} \mathrm{~S}$ можно записать реакцией совместного осаждения сульфидов кадмия и свинца тиомочевиной в щелочной среде:

$$
\begin{aligned}
& x \mathrm{CdL}_{1}^{2+}+(1-x) \mathrm{PbL}_{2}^{2+}+\mathrm{N}_{2} \mathrm{H}_{4} \mathrm{CS}+2 \mathrm{OH}^{-} \\
& \quad=\mathrm{Cd}_{x} \mathrm{~Pb}_{1-x} \mathrm{~S}+x \mathrm{~L}_{1}+(1-x) \mathrm{L}_{2}+\mathrm{H}_{2} \mathrm{CN}_{2}+2 \mathrm{H}_{2} \mathrm{O},
\end{aligned}
$$

где $\mathrm{L}_{1}, \mathrm{~L}_{2}$ - лиганды для кадмия и свинца. Лигандами для кадмия служил аммиак $\left(\mathrm{L}_{1}\right)$, а для свинца цитрат-ионы $\left(\mathrm{L}_{2}\right)$.

Электронно-микроскопические изображения пленок, нанесенных химическим осаждением на подложки из кремния $(a)$, стекла с проводящим слоем ITO $(b)$, ситалла $(c)$, предметного стекла $(d)$, кварца $(e)$ и пористого стекла $(f)$, приведены на рис. 1. Микрофотографии демонстрируют выраженное влияние химического состава и микрорельефа поверхности подложек на микроструктуру осажденных пленок $\mathrm{CdPbS}$. Анализ полученных результатов позволяет высказать предположение о том, что выявленные особенности морфологии пленок определяются условиями их зародышеобразования и роста на подложках различной природы.

Изменение условий взаимодействия исходных компонентов, участвующих в реакции (3), неизменно влечет за собой определенные отличия в процессе зародышеобразования твердой фазы, что в итоге окажет свое влияние на состав и морфологию пленок и соответственно на их функциональные свойства.

Анализ микроструктуры синтезированных пленок показал, что пленка с наиболее высокой плотностью упаковки зерен по поверхности подложки формируется на ориентированном (111) кремнии (рис. 1,a). При этом часть кристаллитов имеет упорядоченные ограненные формы, а другая часть в отличие от первых - неупорядоченные. Такая морфология слоя, по мнению Кукушкина с соавт. [33], наблюдается тогда, когда параметры кристаллических решеток подложки и пленки отличаются более чем на 4\%. В нашем случае эта разница для кремния $\left(a_{\mathrm{Si}}=0.54307\right.$ нм$)$ и пленки на основе сульфида свинца $(a=0.59343$ нм $)$ составляет $\sim 9 \%$.

В свою очередь пленке $\mathrm{CdPbS}$, выращенной на ITOпокрытии, нанесенном на стекло, характерна неоднородная микроструктура со степенью сплошности $\sim 80-85 \%$. Слой состоит из небольшого количества отдельных кристаллитов, между которыми располагаются сплюснутые пирамидки со сглаженными гранями и друзы в форме цветкообразных агрегатов (рис. $1, b)$. Такая неоднородность обусловлена, вероятно, несколькими причинами: разница параметров решеток ITO $\left(a_{\text {Iто }}=1.01-1.03 \mathrm{Hм}\right)[34]$ и пленки достигает $\sim 42 \%$; состав покрытия $\left(\mathrm{In}_{2} \mathrm{O}_{3}\right)_{0.9}\left(\mathrm{SnO}_{2}\right)$ локально неоднороден по поверхности и может включать наряду с кристаллической структурой и аморфные участки поверхности.

На диэлектрических подложках с оксидсодержащими поверхностями (ситалл, стекло, кварц) механизм взаимодействия солей металлов с тиомочевиной при химическом осаждении сульфидов металлов кардинально отличается от процесса конденсации на подложках из кремния и ITO [20]. Особое значение здесь имеет образование гидроксо-коллоидных форм металла $\mathrm{Me}(\mathrm{OH})_{2}$, покрывающих моно- или полимолекулярным слоем гидрофильную поверхность подложки и выступающих в качестве центров зародышеобразования сульфидной фазы $\mathrm{MeS}$ [35]. Но, несмотря на оксидный состав указанных подложек, формирование на них пленок $\mathrm{CdPbS}$ имеет свои особенности.

Так, ситалл СТ-50-1, представляющий собой стеклокерамический материал с полукристаллической структурой, содержит „каталитические добавки“, которые вызывают появление большого количества центров кристаллизации и создают условия для образования мелкокристаллической структуры. Поэтому тонкопленочный слой состоит из отдельных мелких пирамидок со сглаженными гранями либо их агрегатов, примыкающих к более крупным кристаллитам, растущим перпендикулярно поверхности подложки (рис. 1,c).

Несмотря на то что угол смачивания поверхности плавленого кварца равен нулю, хорошо ограненные кристаллиты с прилипшими к ним зернами меньшего размера, не полностью покрывают подложку (рис. 1,d), что, вероятно, определяется особенностями микрорельефа ее поверхности.

Пленка $\mathrm{CdPbS}$ (рис. 1,e), выращенная на предметном стекле и покрывающая не более $65-70 \%$ его поверхности, состоит из хорошо ограненных треугольных пирамид, не имеющих преимущественной ориентации, поскольку поверхность подложки не обладает ориентирующим эффектом. Большинство пирамид достаточно крупные (с размером ребра 300-500 нм), между ними расположены более мелкие с размерами 30-120нм. Образование крупных хорошо ограненных образований обусловлено, вероятно, наличием значительного энергетического барьера при формировании пленки на аморфной подложке, не имеющей большого числа активных центров. В этой связи процесс зародышеобразования осуществляется с участием относительно малого числа зародышей, характеризующихся устойчивым ростом.

Весьма однородной, состоящей из глобул примерно одинакового размера ( $\sim 450 \mathrm{HM})$, в состав которых входят более мелкие сферические частицы преимущественно размером 50-100 нм, выглядит пленка $\mathrm{CdPbS}$ на пористом стекле (рис. $1, f)$. При его получении выщелачиванием натриево-боросиликатных стекол раствором 


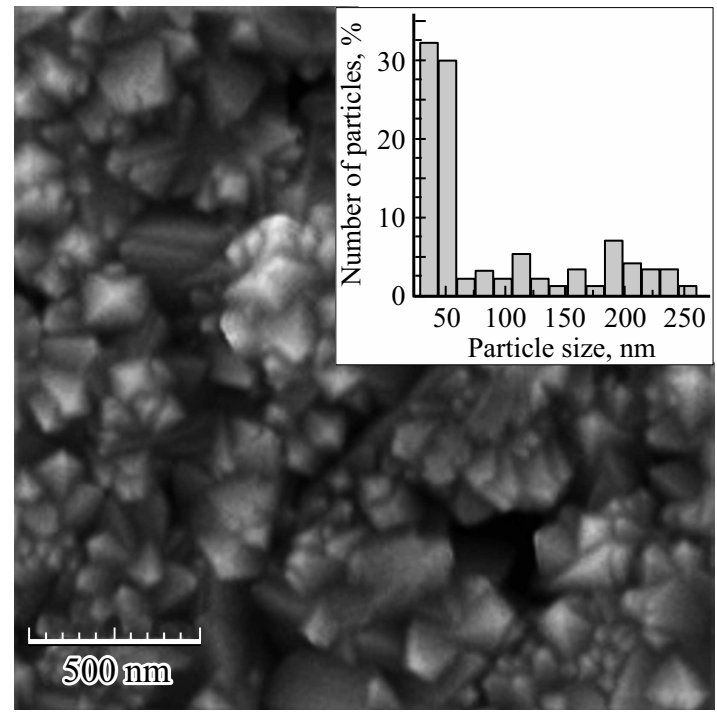

$a$
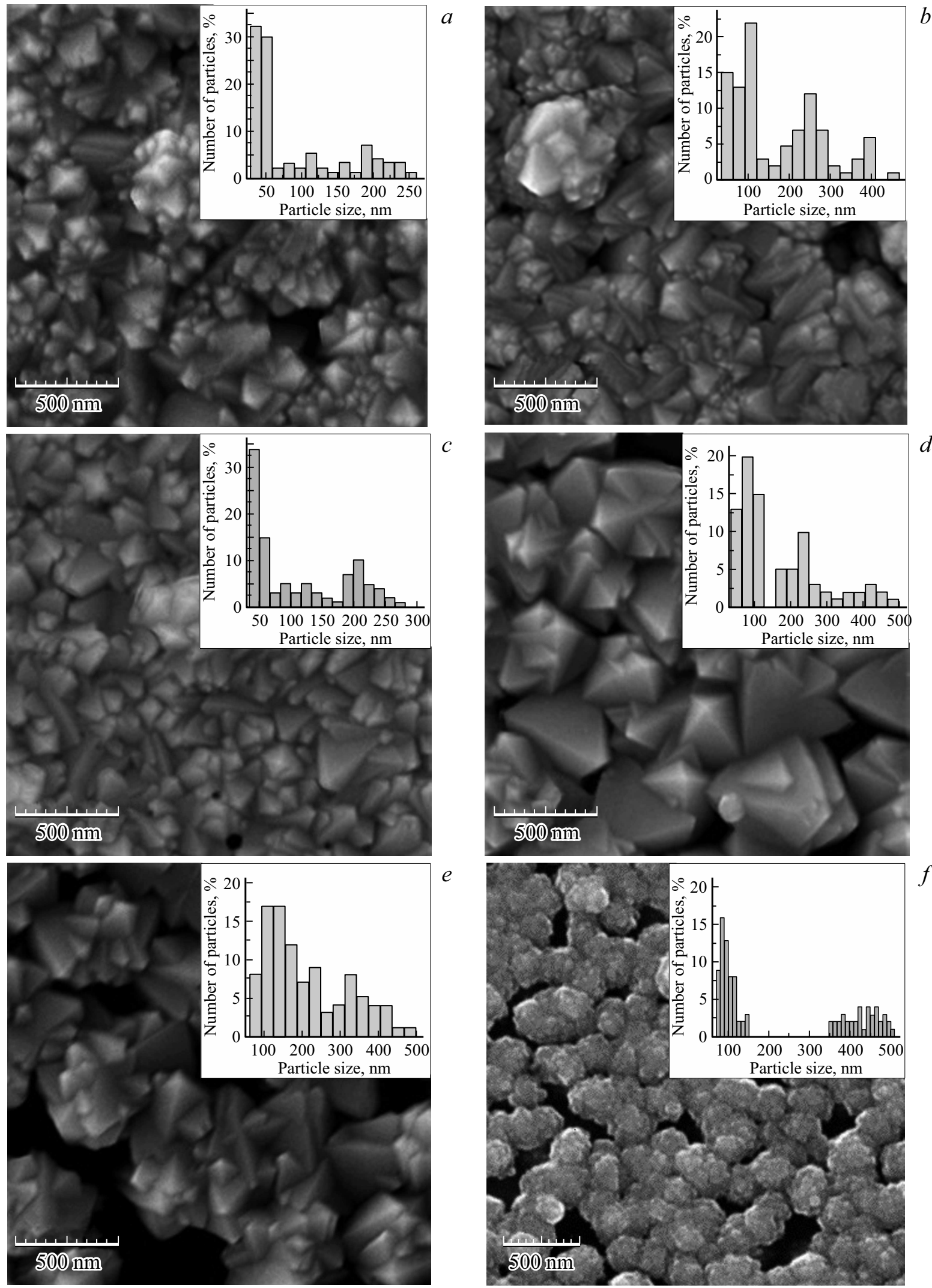

Рис. 1. Электронно-микроскопические изображения пленок $\mathrm{CdPbS}$ на кремнии $(a)$, ITO покрытии, нанесенном на стекло $(b)$, ситалле $(c)$, предметном стекле $(d)$, плавленом кварце $(e)$, пористом стекле $(f)$, и гистограммы распределения частиц по размерам на этих подложках. 
Таблица 1. Состав пленок $\mathrm{Cd}_{x} \mathrm{~Pb}_{1-x} \mathrm{~S}$, осажденных в течение 30 мин на различных подложках при $353 \mathrm{~K}$

\begin{tabular}{|c|c|c|c|c|c|c|c|c|}
\hline \multirow[b]{2}{*}{ Подложка } & \multicolumn{3}{|c|}{$\begin{array}{c}\text { Содержание элементов } \\
\text { в пленке, ат\% }\end{array}$} & \multirow{2}{*}{$\begin{array}{c}\text { Формульный } \\
\text { состав пленки } \\
\text { (без разделения на } \\
\text { кристаллическую } \\
\text { и аморфную фазы) }\end{array}$} & \multirow{2}{*}{$\begin{array}{c}\text { Период } \\
\text { решетки ТР } \\
a_{B 1}(\text { нм }) \\
\pm 0.0001\end{array}$} & \multirow{2}{*}{$\begin{array}{c}\text { Формульный } \\
\text { состав ТР } \\
\mathrm{Cd}_{x} \mathrm{~Pb}_{1-x} \mathrm{~S}, \\
\text { оценка по периоду } \\
\text { решетки, } \pm 0.004\end{array}$} & \multicolumn{2}{|c|}{$\begin{array}{l}\text { Фазовый состав } \\
\text { пленки (мол\%) }\end{array}$} \\
\hline & $\mathrm{Cd} \pm 0.12$ & $\mathrm{~Pb} \pm 0.41$ & $\mathrm{~S} \pm 0.29$ & & & & $\begin{array}{c}\text { твердый } \\
\text { раствор } \\
\mathrm{Cd}_{x} \mathrm{~Pb}_{1-x} \mathrm{~S}\end{array}$ & $\begin{array}{c}\text { аморфный } \\
\text { сульфид } \\
\mathrm{CdS}\end{array}$ \\
\hline $\begin{array}{l}\text { Кремний } \\
(111)\end{array}$ & 6.84 & 44.54 & 48.62 & $\mathrm{Cd}_{0.137} \mathrm{~Pb}_{0.891} \mathrm{~S}_{0.972}$ & 0.5906 & $\mathrm{Cd}_{0.069} \mathrm{~Pb}_{0.931} \mathrm{~S}$ & $\sim 96$ & $\sim 4$ \\
\hline $\begin{array}{l}\text { Проводящий } \\
\text { слой ITO }\end{array}$ & 5.42 & 46.04 & 48.54 & $\mathrm{Cd}_{0.108} \mathrm{~Pb}_{0.921} \mathrm{~S}_{0.971}$ & 0.5908 & $\mathrm{Cd}_{0.063} \mathrm{~Pb}_{0.937} \mathrm{~S}$ & $\sim 98$ & $\sim 2$ \\
\hline Ситалл & 7.16 & 43.47 & 49.37 & $\mathrm{Cd}_{0.143} \mathrm{~Pb}_{0.869} \mathrm{~S}_{0.987}$ & 0.5913 & $\mathrm{Cd}_{0.052} \mathrm{~Pb}_{0.948} \mathrm{~S}$ & $\sim 92$ & $\sim 8$ \\
\hline $\begin{array}{l}\text { Предметное } \\
\text { стекло }\end{array}$ & 7.09 & 43.82 & 49.09 & $\mathrm{Cd}_{0.142} \mathrm{~Pb}_{0.876} \mathrm{~S}_{0.982}$ & 0.5913 & $\mathrm{Cd}_{0.052} \mathrm{~Pb}_{0.948} \mathrm{~S}$ & $\sim 92$ & $\sim 8$ \\
\hline $\begin{array}{l}\text { Плавленый } \\
\text { кварц }\end{array}$ & 5.09 & 45.71 & 49.20 & $\mathrm{Cd}_{0.102} \mathrm{~Pb}_{0.898} \mathrm{~S}_{0.984}$ & 0.5892 & $\mathrm{Cd}_{0.099} \mathrm{~Pb}_{0.901} \mathrm{~S}$ & 100 & 0 \\
\hline $\begin{array}{l}\text { Пористое } \\
\text { стекло }\end{array}$ & 6.78 & 43.85 & 49.37 & $\mathrm{Cd}_{0.136} \mathrm{~Pb}_{0.877} \mathrm{~S}_{0.987}$ & 0.5891 & $\mathrm{Cd}_{0.104} \mathrm{~Pb}_{0.896} \mathrm{~S}$ & 98 & $\sim 2$ \\
\hline
\end{tabular}

$\mathrm{HCl}$ происходит удаление ионов натрия $\mathrm{Na}^{+}$из решетки стекла с образованием пористой структуры, содержащей кислый оксид бора $\mathrm{B}_{2} \mathrm{O}_{3}$. K тому же из-за остаточного содержания после промывки в нанопорах соляной кислоты на поверхности пористого стекла в отличие от предметного стекла и кварца адсорбция гидроксидионов и образование гидроксидных фаз затруднены. На аморфной подложке, содержащей кислотные центры, более вероятным представляется формирование пленки за счет блочного механизма с образованием кластерных частиц непосредственно в объеме реакционной смеси. Рост пленки протекает за счет гетерофазных флуктуаций с участием многоатомных кластеров и их агрегатов, являющихся продуктами структурирования коллоидных частиц сульфидов металлов.

Множественное вторичное зародышеобразование при росте пленки особенно заметно проявляется на кремнии (111), ITO покрытии, ситалле, кварце и в меньшей степени на диэлектрической подложке из предметного стекла, на котором можно увидеть слоистый рост кристаллитов. В отличие от них на пористом стекле происходит рост только первичных зародышей и их объединение в глобульные агрегаты.

Интерпретация экспериментальных результатов распределений частиц по размерам на различных подложках путем обработки микроизображений с помощью программы Measurer 1.00, а также в программе Origin 2018 приведена на рис. 1 (см. вставки).

Анализируя гистограммы размерного ряда зерен, из которых сформированы пленки $\mathrm{CdPbS}$, можно увидеть в них различное количество частиц нанодиапазона. Так, содержание частиц с размерами до 50 и 100 нм составляет соответственно 62 и 70\% (на кремнии), 34 и 60\% (на ситалле), 15 и 50\% (на ITO покрытии), 13 и 36\% (на предметном стекле), 7 и 24\% (на кварце), 8 и 23\% (на пористом стекле).
Достаточно высокая доля наночастиц на поверхности кремниевой подложки $(70 \%)$ обусловлена, как отмечалось выше, высокой плотностью образования на ее поверхности зародышей (рис. 1,a). При осаждении на ситалле, как видно из гистограммы, пленка содержит меньшее количество наночастиц $(60 \%)$, что можно объяснить более сложным рельефом ее поверхности и полукристаллической структурой (рис. 1, c). Неоднородным включением олова в структуру $\mathrm{In}_{2} \mathrm{O}_{3}$ и присутствием наряду с кристаллической структурой аморфных участков ITO покрытия обусловлено снижение до 50\% наночастиц на его поверхности (рис. 1,b). На поверхности предметного стекла уменьшение доли наночастиц до 33\% связано с особенностями его микрорельефа и распределением активных центров (рис. $1, d)$. Примерно одинаковое количество нанодисперсий (23-24\%) участвует в формировании тонкопленочного слоя на кварце (рис. $1, e)$ и пористом стекле (рис. $1, f)$.

Доля частиц в размерном интервале 150-250 нм растет от 17 до 45\% от кремния к кварцу. Исключение составляет пористое стекло, в котором отсутствуют зерна таких размеров. Частиц с размерами 350-500 нм не наблюдается в пленках, осажденных на поверхности кремния и ситалла. Напротив, на кварце их до 13\%, а максимальное количество, достигающее 46\%, на поверхности пористого стекла.

Для установления элементного состава синтезированных пленок был проведен локальный энергодисперсионный микроанализ (EDX) по всей площади поверхности слоев не менее чем в 10 точках. Результаты элементного анализа на содержание свинца, кадмия и серы, приведенные в табл. 1, позволяют заключить, что природа материала подложки оказывает незначительное влияние на состав пленок. Так, относительное содержание свинца в них составило от 43.47 до 46.04 ат\%, а кадмия от 5.09 до 7.16 ат\%. Соотношение суммы металлов к 
халькогену, составившее 1.3-1.06, указывает на некоторый недостаток по сере. Нарушение стехиометрического соотношения между катионной и анионной частью связано, вероятно, с наличием вакансий в подрешетке халькогена.

\section{2. Кристаллическая структура}

На рентгенограммах всех пленок $\mathrm{CdPbS}$, синтезированных на изучаемых подложках, присутствуют отражения кубической $B 1$ (пр. гр. $F m \overline{3} m$ ) структуры (рис. 2). Как видно из табл. 1, период кубической фазы во всех случаях находится в интервале от 0.5891 до $0.5913 \mathrm{Hм}$, что меньше периода кубического сульфида свинца $\mathrm{PbS}$ (0.5934(3) нм), определенного нами ранее [36]. Это обусловлено замещением более крупных ионов свинца $\left(r_{\mathrm{Pb}^{2+}}=0.120 \mathrm{HM}\right)$ в кристаллической решетке $\mathrm{PbS}$ на меньшие по размеру ионы кадмия $\left(r_{\mathrm{Cd}^{2+}}=0.097 \mathrm{Hм}\right)$ [37] $)$. Если предположить, что период кубической решетки при замещении свинца в $\mathrm{PbS}$ кадмием меняется по правилу Вегарда, то, используя значения постоянных кристаллической решетки $\mathrm{PbS}(0.5934(3)$ нм) и $\mathrm{CdS}(0.5516$ нм $)$ [38-40], имеющих кубическую $B 1$ структуру, можно оценить содержание кадмия в образующихся твердых растворах замещения $\mathrm{Cd}_{x} \mathrm{~Pb}_{1-x} \mathrm{~S}$. Согласно выполненной оценке, составы твердых растворов с периодом кристаллической решетки $0.5906,0.5908,0.5913,0.5892,0.5891$ нм соответственно имеют формульный состав $\mathrm{Cd}_{0.069} \mathrm{~Pb}_{0.931} \mathrm{~S}$ (кремний), $\mathrm{Cd}_{0.063} \mathrm{~Pb}_{0.937} \mathrm{~S}$ (ITO), $\mathrm{Cd}_{0.052} \mathrm{~Pb}_{0.948} \mathrm{~S}$ (ситалл и предметное стекло), $\mathrm{Cd}_{0.099} \mathrm{~Pb}_{0.901} \mathrm{~S}$ (плавленый кварц), $\mathrm{Cd}_{0.104} \mathrm{~Pb}_{0.896} \mathrm{~S}$ (пористое стекло). Отметим, что установленное содержание кадмия в решетке $\mathrm{PbS}$ в 10-20 раз превышает его равновесную концентрацию в твердых растворах $\mathrm{Cd}_{x} \mathrm{~Pb}_{1-x} \mathrm{~S}$ для изучаемых условий [41], т.е. осажденные в работе пленки твердых растворов являются пересыщенными по замещающему компоненту.

Обратим внимание на то, что общее содержание кадмия в пленках, установленное EDX анализом, как правило, выше, чем в составе твердого раствора $\mathrm{Cd}_{x} \mathrm{~Pb}_{1-x} \mathrm{~S}$, оцененном по изменению периода решетки. Таким образом, осажденные слои помимо кристаллического твердого раствора $\mathrm{Cd}_{x} \mathrm{~Pb}_{1-x} \mathrm{~S}$ со структурой $B 1$ содержат рентгеноаморфный сульфид кадмия (табл. 1). Исключение составляет пленка на подложке из плавленого кварца, которая однофазна и содержит только кубический твердый раствор $\mathrm{Cd}_{x} \mathrm{~Pb}_{1-x} \mathrm{~S}$. Пленки твердых растворов, полученные на ITO, пористом стекле, кремнии, ситалле и предметном стекле, дополнительно содержат от 2 до 8 мол\% ренетгеноаморфного сульфида кадмия CdS. При этом его количество минимально в пленках на пористом стекле и ITO и возрастает до максимальных значений на ситалле и предметном стекле. Промежуточное положение занимают пленки на кремнии. Выявленные особенности связаны с различиями как в химическом составе и кристаллографических характеристиках материала подложек, так и в микрорельефе их поверхности, что самым непосредственным
Таблица 2. Количество зерен с преимущественной ориентацией (200), параллельной плоскости пленки $\mathrm{T}_{(200)}$, среднее значение микродеформаций по объему образца $(\langle\Delta d / d\rangle)$ и размер областей когерентного рассеяния $(D)$

\begin{tabular}{l|c|c|c}
\hline \multicolumn{1}{c|}{ Тип подложки } & $\mathrm{T}_{(200)}, \%$ & $\langle\Delta d / d\rangle, \cdot 10^{-4}$ & $\mathrm{D}$, нм \\
\hline Кремний & 40.4 & 34.1 & 268 \\
Стекло + ITO & 38 & 44.1 & 243 \\
Ситалл & 29.2 & 26.5 & 230 \\
Предметное стекло & 2.2 & 13.4 & 164 \\
Плавленый кварц & 63.4 & 30.6 & 177 \\
Пористое стекло & - & 236 & 75
\end{tabular}

образом отражается на процессе зародышеобразования. Как отмечалось ранее, оксидный характер ситалла и предметного стекла в большей степени способствует локальному повышению $\mathrm{pH}$ подложки и образованию на ее поверхности мономолекулярного слоя гидроксида кадмия, который в дальнейшем сульфидизируется до CdS. Присутствие в составе пористого стекла и кварца кислотных центров $\mathrm{B}_{2} \mathrm{O}_{3}$ и $\mathrm{SiO}_{2}$ приводит к локальному понижению $\mathrm{pH}$, затрудняющему образование гидроксида, а затем сульфида кадмия. Таким образом, доля рентгеноаморфного сульфида кадмия в составе пленки зависит и от кислотно-основных свойств подложки.

Визуальные наблюдения за реакционной смесью показали, что процесс осаждения пленок на ситалле и стекле начинается с образования аморфной фазы сульфида кадмия, к 15-й минуте от начала осаждения почти вся поверхность желтого зародышевого слоя $\mathrm{CdS}$ покрывается растущими зернами $\mathrm{Cd}_{x} \mathrm{~Pb}_{1-x} \mathrm{~S}$ серого цвета. Косвенным подтверждением присутствия широкозонного рентгеноаморфного $\mathrm{CdS}$ в пленке является ее омическое сопротивление. Так, пленки на предметном стекле и ситалле, содержащие максимальные $\sim 8$ мол\% $\mathrm{CdS}$, имеют соответственно сопротивление 300 и $120 \mathrm{MOM}$ на квадрат. Уменьшение содержания сульфида кадмия до $\sim 4$ мол\% в составе пленки $\mathrm{Cd}_{x} \mathrm{~Pb}_{1-x} \mathrm{~S}$, осажденной на кремнии (111), а также до $\sim 2$ мол\% на ITO и пористом стекле приводит к снижению омического сопротивления до 18.1, 15 и 14 Мом на квадрат соответственно. Пленки, сформированные на плавленом кварце, в которых рентгеноаморфный сульфид кадмия отсутствует, имеют темновое сопротивление $\sim 7.8$ Мом на квадрат.

При создании градиента температуры в области зондовых контактов по знаку термоэдс был установлен $n$-тип проводимости всех синтезированных пленок, что согласуется с EDX анализом, установившим наличие нестехиометрии в пользу суммы металлов $(\mathrm{Cd}+\mathrm{Pb})$.

Анализ рентгенограмм, выполненный методом полнопрофильного анализа Ритвелда с использованием программного пакета Fullprof, свидетельствует о различном соотношении интенсивностей дифракционных отражений, отчетливо наблюдаемых для граней (111) и (200). Наиболее текстурированная пленка с коэффициентом 

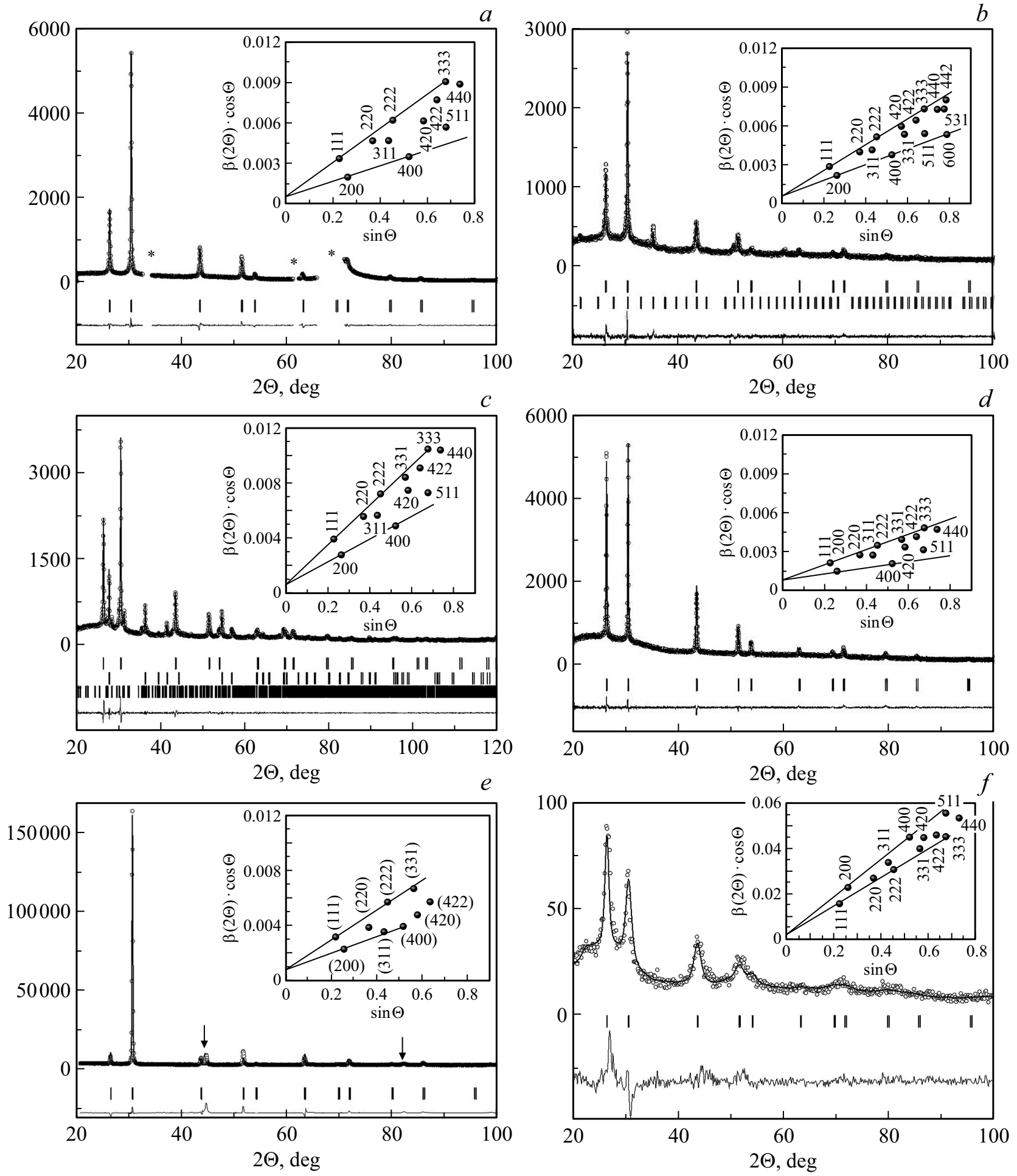

Рис. 2. Экспериментальные (кружки) и расчетные (огибающие линии) рентгенограммы пленок твердых растворов $\mathrm{Cd}_{x} \mathrm{~Pb}_{1-x} \mathrm{~S}$, осажденных на кремний $(a)$, исключены рефлексы $\mathrm{Si}$; ITO-покрытие $(b)$, нижние штрихи - фаза $\operatorname{In}_{2} \mathrm{O}_{3}$; ситалл $(c)$, средние штрихи - фаза $\mathrm{TiO}_{2}$, нижние - кордиерит; предметное стекло $(d)$, плавленый кварц $(e)$ и пористое стекло $(f)$. В нижней части рисунков приведена разность между экспериментальной и расчетной рентгенограммами. Штрихами показаны угловые положения рефлексов фазы $B 1$ и подложек. На вставке в одинаковом масштабе показана зависимость $\beta(2 \Theta) \cdot \cos \Theta$ от $\sin \Theta$.

текстуры $\mathrm{T}_{(200)}$, равным $63.4 \%$ в направлении (200), синтезирована на кварце. Несколько меньше коэффициент текстуры $\mathrm{T}_{(200)}$ на кремнии $(40.4 \%$,), ITО-покрытии
(38\%) и ситалле (29.2\%). Минимальное его значение $(2.2 \%)$ наблюдается на подложке из предметного стекла (табл. 2). 
Галообразный характер рентгенограммы пленки $\mathrm{Cd}_{x} \mathrm{~Pb}_{1-x} \mathrm{~S}$, синтезированной на поверхности пористого стекла, наглядно свидетельствует об отсутствии ее текстурированности. Поры, находящиеся на поверхности подложки, увеличивают случайность зарождения новой фазы и тем самым ухудшают ориентацию слоев.

Разностные кривые на рис. 2 свидетельствуют о хорошем согласии экспериментальных и расчетных рентгенограмм пленок твердых растворов $\mathrm{Cd}_{x} \mathrm{~Pb}_{1-x} \mathrm{~S}$, осажденных на подложки из монокристаллического кремния $(111)(a)$, ITO-покрытия $(b)$ ситалла $(c)$, предметного стекла $(d)$, плавленого кварца $(e)$ и пористого стекла $(f)$.

Дифракционные отражения, наблюдаемые на рентгенограммах всех синтезированных тонкопленочных слоев, уширены по сравнению с эталонным разрешением прибора из-за малого размера частиц и наличия в пленках микронапряжений.

Разделение размерного и деформационного вкладов в уширение отражений и оценка среднего размера областей когерентного рассеяния, принимаемого как средний размер $(D)$ частиц, выполнены экстраполяционным методом Вильямсона-Холла.

Согласно оценке экспериментальной зависимости $\beta(2 \Theta) \cdot \cos \Theta=f(\sin \Theta)$ можно сделать вывод о том, что эквивалентные плоскости (111), (222) и (200), (400) отсекают на оси ординат примерно равные отрезки (см. вставки на рис. 2, $a-e$ ). Это говорит о том, что, во-первых, области когерентного рассеяния $(D)$ имеют изотропную форму, а, во-вторых, их размеры близки. Об этом свидетельствуют приведенные в табл. 2 результаты оценки среднего размера частиц в пленках твердых растворов $\mathrm{Cd}_{x} \mathrm{~Pb}_{1-x} \mathrm{~S}$, осажденных на изучаемые подложки. Так, на кремнии он составляет 268 нм, ITO-покрытии 243 нм, ситалле - 230 нм, кварце - 177 нм, предметном стекле - 163 нм и пористом стекле - 75 нм. Найденные величины удовлетворительно согласуются с данными электронной микроскопии.

Наблюдаемые уширения рефлексов обусловлены и внутренними микронапряжениями $\Delta d / d$ в объеме исследуемых пленок, а нерегулярность в расположении точек на вставках рис. 2 позволяет констатировать существование в них анизотропии напряжений. Авторы работ $[42,43]$ полагают, что деформационная анизотропия уширения рефлексов в образцах может быть вызвана наличием дефектов и дислокаций при замещении более крупного атома свинца на меньший по размеру кадмий, способствуя уплотнению структуры, уменьшению длины связи и искажению кристаллической решетки сульфида свинца.

В частности, микронапряжения $\Delta d / d$, возникающие в тонкопленочном слое $\mathrm{Cd}_{x} \mathrm{~Pb}_{1-x} \mathrm{~S}$, сформированном на стекле, составляют $13.4 \cdot 10^{4}$, ситалле $\left(26.5 \cdot 10^{4}\right)$, кремнии $\left(34.1 \cdot 10^{4}\right)$, ITО-покрытии на стекле $\left(44.1 \cdot 10^{4}\right)$ и кварце $\left(63.4 \cdot 10^{4}\right)$.

Обращает на себя внимание пленка на пористом стекле, для которой средние значения величины $\beta(2 \Theta) \cdot \cos \Theta$ близки $\Theta$ при $\sin \Theta$, стремящемся к нулю (см. вставку на рис. $2, f$ ), т. е. уширение дифракционных отражений главным образом связано с возникновением микронапряжений $\Delta d / d$ в обсуждаемой пленке. Поэтому наиболее деформированной оказалась пленка на пористом стекле, микронапряжения в которой достигают $236 \cdot 10^{4}$. Хотя, казалось бы, что энергетически выгоднее зарождение новой фазы в порах, однако их малый размер 4.5-5.0 нм затрудняет рост критических зародышей осаждаемой фазы, размер которых, по данным [20,35], составляет $3.2-3.8$ нм. Отсюда случайность зарождения резко снижает ориентационные свойства поверхности подложки, в результате чего пленка растет более дефектной и напряженной.

\section{3. Механические напряжения}

В связи с перспективами создания функциональных устройств на основе твердых растворов $\mathrm{Cd}_{x} \mathrm{~Pb}_{1-x} \mathrm{~S}$ в наноэлектронике, сенсорике и гелиоэнергетике актуальна проблема механических напряжений на интерфейсе „пленка-подложка“. Они обусловлены, в частности, различием постоянных кристаллических решеток, модулей упругости, коэффициентов термического расширения пленки и подложки. Поскольку они жестко связаны друг с другом, пленка (существенно тоньше подложки) может испытывать механические напряжения сжатия или растяжения, чтобы соответствовать размеру субстрата [23]. Однако расчет механических напряжений в системе „пленка-подложка“ является достаточно сложным. Между тем важна даже их приближенная оценка, которая позволит качественно определить распределение напряжений на исследуемых подложках.

В настоящей работе количественная оценка величины упругих напряжений, возникающих на межфазной границе „пленка $\mathrm{Cd}_{x} \mathrm{~Pb}_{1-x} \mathrm{~S}$-подложка“ была проведена по выше приведенной формуле (2). Физические характеристики (модуль Юнга $E$, температурный коэффициент расширения $\alpha$, коэффициент Пуассона $v$ ) многокомпонентного соединения $\mathrm{Cd}_{x} \mathrm{~Pb}_{1-x} \mathrm{~S}$, сформированного на основе бинарных сульфидов свинца и кадмия, были рассчитаны исходя из условия их аддитивного изменения в составе твердого раствора и справочных сведений для сульфидов $\mathrm{PbS}$ и $\mathrm{CdS}$. Для расчета были использованы следующие сведения для индивидуальных фаз $\mathrm{PbS}$ и CdS [44]:

\begin{tabular}{c|c|c|c} 
& $\alpha \cdot 10^{6}, \mathrm{~K}^{-1}$ & $E$, Гпа & $v$ \\
$\mathrm{PbS}$ & 19 & 70.2 & 0.38 \\
$\mathrm{CdS}$ & 2.5 & 42.0 & 0.28
\end{tabular}

Характеристики изучаемых подложек и пленок осажденных твердых растворов $\mathrm{Cd}_{x} \mathrm{~Pb}_{1-x} \mathrm{~S}$, а также рассчитанные для них, исходя из состава, величины температурного коэффициента расширения $\alpha$, модуля Юнга $E$, коэффициента Пуассона $v$ и возникающие упругие механические напряжения на интерфейсе „пленка-подложка“ $\sigma_{\Delta \alpha}$ приведены в табл. 3. 
Таблица 3. Характеристики подложек и пленок твердых растворов $\mathrm{Cd}_{x} \mathrm{~Pb}_{1-x} \mathrm{~S}$ : температурный коэффициент расширения $\alpha$, модуль Юнга $E$, коэффициент Пуассона $v$, толщины подложки и пленки $h_{\text {sub }}, h_{\mathrm{Cd}_{x} \mathrm{~Pb}_{1-x} \mathrm{~s}}$, механические напряжения на интерфейсе „пленка-подложка“ $\sigma_{\Delta \alpha}$

\begin{tabular}{|c|c|c|c|c|c|c|c|c|}
\hline \multicolumn{3}{|c|}{ Характеристики подложек } & \multicolumn{5}{|c|}{ Состав и характеристики пленок } & \multirow{2}{*}{$\begin{array}{c}\text { Механические } \\
\text { напряжения }\end{array}$} \\
\hline Тип & $\alpha \cdot 10^{6}, \mathrm{~K}^{-1}$ & h, MM & Состав пленки & $\alpha \cdot 10^{6}, \mathrm{~K}^{-1}$ & h, MM & $E_{\mathrm{Cd}_{x} \mathrm{~Pb}_{1-x} \mathrm{~S}}$, ГПа & $v_{\mathrm{Cd}_{x} \mathrm{~Pb}_{1-x} \mathrm{~S}}$ & \\
\hline Пористое стекло & 13 & 1 & $\begin{array}{l}\mathrm{Cd}_{0.104} \mathrm{~Pb}_{0.896} \mathrm{~S} \\
+2 \text { мол\% } \mathrm{CdS}\end{array}$ & 17.28 & 190 & 67.27 & 0.37 & -9.32 \\
\hline Стекло + ITO & 9.5 & $\begin{array}{c}1+ \\
0.0001\end{array}$ & $\begin{array}{l}\mathrm{Cd}_{0.063} \mathrm{~Pb}_{0.937} \mathrm{~S} \\
+2 \text { мол\% } \mathrm{CdS}\end{array}$ & 17.96 & 185 & 68.43 & 0.374 & - \\
\hline Предметное стекло & 8.3 & 1 & $\begin{array}{l}\mathrm{Cd}_{0.052} \mathrm{~Pb}_{0.948} \mathrm{~S} \\
+8 \text { мол\% } \% \mathrm{CdS}\end{array}$ & 18.14 & 190 & 68.73 & 0.375 & -21.79 \\
\hline Ситалл & 5.0 & 0.51 & $\begin{array}{l}\mathrm{Cd}_{0.052} \mathrm{~Pb}_{0.948} \mathrm{~S} \\
+8 \text { мол\% } \mathrm{CdS}\end{array}$ & 18.14 & 190 & 68.73 & 0.375 & -45.6 \\
\hline Кремний (111) & 2.82 & 0.4 & $\begin{array}{l}\mathrm{Cd}_{0.069} \mathrm{~Pb}_{0.931} \mathrm{~S} \\
+4 \text { мол\% } \mathrm{CdS}\end{array}$ & 17.86 & 185 & 68.25 & 0.373 & -87.62 \\
\hline Плавленый кварц & 0.56 & 0.31 & $\mathrm{Cd}_{0.099} \mathrm{~Pb}_{0.901} \mathrm{~S}$ & 17.37 & 190 & 67.41 & 0.37 & -121.79 \\
\hline
\end{tabular}

Как отмечается многими исследователями, определяющую роль в возникновении механических напряжений в подобных системах играют различия в температурных коэффициентах расширения между пленкой и субстратом. Заметим, что значения температурных коэффициентов расширения для синтезированных соединений: от $17.28 \cdot 10^{-6}$ до $18.14 \cdot 10^{-6} \mathrm{~K}^{-1}$. Для приведенных подложек значения температурных коэффициентов расширения уменьшаются, в частности, от $13 \cdot 10^{-6}$ для пористого стекла до $0.56 \cdot 10^{-6} \mathrm{~K}^{-1}$ для плавленого кварца. С учетом этих значений механические напряжения, возникающие на интерфейсе ,пленка-подложка“, в этом же правлении возрастают в абсолютном выражении от -9.32 до -121.79 кН/м². Полученные значения механических напряжений отрицательны, означают, что пленки подвергаются механическим напряжениям сжатия, в результате которых возможно растрескивание слоя или ухудшение адгезии пленки к подложке, особенно на интерфейсе „пленка $\mathrm{Cd}_{0.099} \mathrm{~Pb}_{0.901} \mathrm{~S}$ - плавленый кварц“.

Как видно из табл. 3, минимальные механические напряжения характерны для межфазной границы „пленкапористое стекло“. Это обусловлено двумя причинами: малым значением температурного коэффициента расширения для него, а также благодаря наличию в нем пор. За счет пористой структуры, как отмечали авторы работ [24-26], повышается „Податливость“ подложки, т. е. возможность ее подстраивания под кристаллическую структуру растущего на ней соединения.

Отдельно стоит рассмотреть подложки, представляющие кристаллические соединения, в частности ориентированный кремний (111) и стекло с нанесенным слоем ITO. Несоответствие параметров кристаллических решеток $(\sim 9 \%)$ и различие коэффициентов термического расширения $(\sim 6 \%)$ между $\mathrm{Si}(111)$ и пленкой $\mathrm{Cd}_{0.069} \mathrm{~Pb}_{0.931} \mathrm{~S}$ с 4 мол\% $\mathrm{CdS}$ создают механические напряжения, достигающие $-87.62 \mathrm{\kappa H} / \mathrm{M}^{2}$.
Отметим, что используемая в работе формула для расчета напряжений применима для двухслойных структур. Для трехслойной структуры (в случае использования ITO-покрытия), состоящей из стекла толщиной $1 \mathrm{MM}$, слоя ITO $(100 \mathrm{HM})$ и пленки $\mathrm{Cd}_{0.063} \mathrm{~Pb}_{0.937} \mathrm{~S}$ толщиной 185 нм, содержащей 2 мол\% $\mathrm{CdS}$, результаты расчета упругих механических напряжений будут не вполне корректны. Добавим также, что слой ITO и обсуждаемая пленка соизмеримы по толщине. Можно лишь предположить, что механические напряжения здесь должны быть достаточно высокими, так как различия параметров кристаллических решеток ITO ( $a=1.0125$ нм [45]) и пленки $\mathrm{Cd}_{0.063} \mathrm{~Pb}_{0.937} \mathrm{~S}(0.5908$ нм$)$ с содержанием 2 мол\% $\mathrm{CdS}$ составляют $\sim 42 \%$, а коэффициентов термического расширения достигают $\sim 47 \%$.

\section{4. Заключение}

Морфология тонкопленочных слоев $\mathrm{CdPbS}$, полученных химическим осаждением на подложках различной природы, свидетельствует о различных механизмах зарождения и роста пленок. Высокая плотность распределения зерен новой фазы по поверхности характерна полупроводниковому кремнию, а на слое ITO, содержащем как кристаллическую структуру, так и аморфные участки, наблюдается неоднородность распределения частиц. На подложках оксидной природы (ситалл, стекло) в качестве центров зародышеобразования могут выступать гидроксоколлоидные формы $\mathrm{Me}(\mathrm{OH})_{2}$, образующие на их поверхности моно- или полимолекулярные слои. На пористом стекле формирование пленки происходит по блочному механизму за счет коллоидных частиц сульфидов $\mathrm{PbS}$ и $\mathrm{CdS}$, образующихся в объеме реакционной смеси.

Энергодисперсионным анализом установлено, что соотношение суммы металлов $(\mathrm{Cd}+\mathrm{Pb})$ к халькогену $(\mathrm{S})$, 
составившее $1.3-1.06$, указывает на нарушение стехиометрии, вызванное вакансиями в подрешетке серы, что косвенно подтверждается $n$-типом проводимости.

Анализом элементного и фазового состава показано, что однофазная пленка твердого раствора $\mathrm{Cd}_{x} \mathrm{~Pb}_{1-x} \mathrm{~S}$ получена лишь на кварцевой подложке, на остальных исследуемых подложках сформированы двухфазные слои, содержащие наряду с твердым раствором $\mathrm{Cd}_{x} \mathrm{~Pb}_{1-x} \mathrm{~S}$ $(0.052<x<0.104)$ от 2 до 8 мол\% рентгеноаморфной фазы сульфида кадмия.

Осаждение пленок $\mathrm{Cd}_{x} \mathrm{~Pb}_{1-x} \mathrm{~S}$ на поверхности нанопористого боросиликатного стекла, предварительно подвергнутого кислотному выщелачиванию, фактически исключает реализацию гидроксидной схемы зарождения с образованием адгезионно прочного подслоя, что приводит к повышению в них величины микронапряжений до $236 \cdot 10^{4}$. Микронапряжения, возникающие в объеме пленок, сформированных на остальных подложках, существенно ниже, составляют от $13.4 \cdot 10^{4}$ до $63.4 \cdot 10^{4}$. Рассчитанные с учетом фазового состава и характеристик индивидуальных сульфидов свинца и кадмия, механические напряжения сжатия, возникающие на интерфейсе „пленка-подложка“ увеличивающиеся в абсолютных значениях в ряду пористое стекло-предметное стекло-ситалл-кремний (111)-плавленый кварц с -9.32 до $-121.79 \kappa \mathrm{H} / \mathrm{m}^{2}$, асимбатны значениям температурных коэффициентов расширения этих подложечных материалов.

\section{Финансирование работы}

Работа выполнена при финансовой поддержке программы 211 Правительства Российской Федерации № 02.A03.21.0006, грантов РФФИ 20-48-660041p_a и No 18-29-11051мк, а также государственного задания МИНОБРНАУКИ России (тема „Поток“ № AAAA-A18-118020190112-8).

\section{Конфликт интересов}

Авторы заявляют, что у них нет конфликта интересов.

\section{Список литературы}

[1] P.L. Nichols, Z. Liu, L. Yin, S. Turkdogan, F. Fan, C.Z. Ning. Nano Lett., 15, 909 (2015).

[2] S.M. Ahmada, S.J. Kasima, L.A. Latif. Jordan J. Physics, 9, 113 (2016).

[3] И.В. Зарубин, В.Ф. Марков, Л.Н. Маскаева, Н.В. Зарубина, М.В. Кузнецов. Журн. аналит. химии, 72, 266 (2017).

[4] А.Е. Бездетнова, В.Ф. Марков, Л.Н. Маскаева, Ю.Г. Шашмурин, А.С. Франц. Журн. аналит. химии, 74, 1256 (2019).

[5] J. Hernadez-Borja, Y.V. Vorobiev, R. Ramirez-Bon. Sol. Energy Mater. Solar Cells, 95, 1882 (2011).

[6] A.S. Obaid, M.A. Mahdi, Z. Hasson, M. Bououdina. Superlatt. Microstr., 52, 816 (2012).

[7] M.A. Barote, S.S. Kamble, A.A. Yadav, R.V. Suryavanshi, L.P. Deshmukh, E.U. Masumdar. Mater. Lett., 78, 113 (2012).
[8] G. Hodes. Phys. Chem. Chem. Phys., 9, 2181 (2007).

[9] G.-L. Tan, L. Liu., W. Wu. AIP Adv., 4, 067107 (2014).

[10] K.E. Suryavanshi, R.B. Dhake, A.M. Patil. Int. J. Sci. Res., 2, 858 (2014).

[11] J.C. Osuwa, C.I. Oriaku, F.I. Ezema. Chalcogenide Lett., 6, 385 (2009).

[12] E. Pentia, V. Draghici, G. Sarau, B. Mereu, L. Pintilie, F. Sava, M. Popescu. J. Electrochem. Soc., 151, G729 (2004).

[13] Л.Н. Маскаева, А.Д, Кутявина, В.Ф. Марков, И.В. Ваганова, В.И. Воронин. ЖОХ, 88, 319 (2018).

[14] E. Rabinovich, E. Wachtel, G. Hodes. Thin Sol. Films, 517, 737 (2008).

[15] M. Kamruzzman, R. Dutta, J. Podder. ФТП, 46, 979 (2012).

[16] Л.Н. Маскаева, И.В. Ваганова, В.Ф. Марков, В.И. Воронин. ЖПХ, 90, 553 (2017).

[17] I.V. Vaganova, L.N. Maskaeva, V.F. Markov, V.I. Voronin, V.G. Bamburov. Nanosystems: physics, chemistry, mathematics, 9, 811 (2018).

[18] O.P. Moreno, M.Ch. Portillo, M.M. Flores, J.M. Juárez, G.A. Ávila, R.L. Morales, O.Z. Ángel. J. Mater. Sci. Eng., A1, 759 (2011).

[19] S.R. Deoa, A.K. Singhb, L. Deshmukha, L.J. Paliwalc, R.S. Singhda. Optik, 126, 2311 (2015).

[20] В.Ф. Марков, Л.Н. Маскаева, П.Н. Иванов. Гидрохимическое осаждение пленок сульфидов металлов: моделирование и эксперимент (Екатеринбург, УрО РАН, 2006).

[21] В.Ф. Марков, Л.Н. Маскаева, Ю.С. Поликарпова. Бутлеровские сообщения, 8, 54 (2006).

[22] И.В. Ваганова, Л.Н. Маскаева, В.И. Воронин, В.Ф. Марков, В.Г. Бамбуров. ДАН, 484, 554 (2019).

[23] А.Р. Шугуров, А.В. Панин. Физическая мезомеханика, 12, 23 (2009).

[24] В.П. Бондаренко, Н.Н. Ворозов, В.В. Дикарева, А.М. Дорофеев, В.И. Левченко, Л.И. Постнова, Г.Н. Троянова. Письма ЖТФ, 20, 51 (1994).

[25] В.И. Левченко, Л.И. Постнова, Е.Л. Труханова, В.П. Бондаренко. Кр. сообщ. Докл. БГУИР, 6, 100 (2015).

[26] C.C. Chang, C. H. Lee. J. Mater. Sci., 36, 3801 (2001).

[27] Л.Н. Маскаева Л.Н., В.Ф. Марков, Е.А. Федорова, М.В. Кузнецов. ЖПХ, 91, 1346 (2018).

[28] H.M. Rietveld. J. Appl. Crystallogr., 2, 65 (1969).

[29] D.L. Bush, J.E. Post. Rev. Mineral., 20, 369 (1990).

[30] J. Rodriges-Carvajal. Physica B, 192, 55 (1990).

[31] G.K. Williamson, W.H. Hall. Acta Metallurgica, 1, 22 (1953).

[32] Ф.Д. Касимов, А.Э. Лютфалибекова. Технология и конструирование в электронной аппаратуре, 2, 13 (2002).

[33] С.А. Кукушкин, А.В. Осипов, В.Н. Бессолов, Н.А. Феоктистов. ФТТ, 56, 1457 (2014).

[34] П.Н. Крылов, Р.М. Закирова, И.В. Федотова, Ф.З. Гильмутдинов. ФТП, 47, 859 (2013).

[35] В.Ф. Марков, Л.Н. Маскаева. Изв. АН. Сер. хим., 7, 1523 (2014).

[36] Л.Н. Маскаева, Е.В. Мостовщикова, В.И. Воронин, Е.Э. Лекомцева, П.С. Богатова, В.Ф. Марков. ФТП, 54, 1041 (2020).

[37] S. Ruben. Handbook of elements (Open Court Publishing Company, Peru, 1999).

[38] P.M. Bethke, P.B. Barton. J. Amer. Miner., 56, 2034 (1971).

[39] R.A. Robie, P.M. Bethke, K.M. Beardsley. U.S. GeoI. Surv. Bull., 1248, 87 (1967).

[40] R.A. Robie, P.M. Bethke, M.S. Toulmin, J.L. Edwards. Geol. Soc. Amer. Mem., 97, 27 (1966). 
[41] В.Н. Томашик, В.Н. Грыцив. Диаграммы состояния систем на основе соединений $\mathrm{A}^{\mathrm{II}} \mathrm{B}^{\mathrm{VI}}$. Справочник (Киев, Наук. думка, 1982).

[42] T. Ungar, I. Dragomir, A. Revesz, A. Borbely. J. Appl. Cryst., 32, 992 (1999).

[43] T. Ungar, A. Borbely. Appl. Phys. Lett., 69, 3173 (1996).

[44] M.J. Weber. Handbook Laser Science and Technology ( CRC Press LLC, 2003) p. 499.

[45] N. Nadaud, M. Nanot, Ph. Boch. J. Am. Ceram. Soc., 77, 843 (1994).

Редактор Г.А. Оганесян

\section{Influence of the substrate nature on the composition CdPbS films and mechanical stresses on the „film-substrat" interface}

L.N. Maskaeva1 , A.V. Pozdin', V.F. Markov 1,2, V.I. Voronin $^{3}$

${ }^{1}$ Ural Federal University named after the first President of Russia B.N. Yeltsin, 620002 Yekaterinburg, Russia

2 Ural State Fire Service Institute of Emergency Ministry of Russia, 620062 Yekaterinburg, Russia

${ }^{3}$ Miheev Institute of Metal Physics of Ural Branch of Russian Academy of Sciences, 620108 Yekaterinburg, Russia

Abstract The role of substrates of different nature has been studied on the phase composition, morphology, and mechanical stresses on the "film-substrate" interface during the chemical deposition of $\mathrm{CdPbS}$ layers on silicon (100), sitall, fused quartz, ITO coating, object and porous glass. It was suggested that the revealed features are associated with different conditions of nucleation and growth of films. It was found that a single-phase film of a $\mathrm{Cd}_{x} \mathrm{~Pb}_{1-x} \mathrm{~S}$ solid solution forms on fused quartz, in contrast to other substrates, on which layers are deposited containing additionally from 2 to $8 \mathrm{~mol} \%$ of the $X$-ray amorphous $\mathrm{CdS}$ phase. It is shown that the magnitude of the mechanical compressive stresses on the "film-substrate“ interface increases from -9.32 to $-121.79 \mathrm{kN} / \mathrm{m}^{2}$ in the series porous glass-object glass-sitall-silicon (111)-fused quartz asymptotically to the values of the temperature expansion coefficients of materials. 